\title{
SCHWANNOMA IN A YOUNG MALE BREAST: A DIFFICULT DIFFERENTIAL DIAGNOSIS
}

Minakshi Gadhire ${ }^{1}$, Prashant Rao ${ }^{2}$, Sarika Mayekar³, Mohan Joshi ${ }^{4}$

\section{HOW TO CITE THIS ARTICLE:}

Minakshi Gadhire, Prashant Rao, Sarika Mayekar, Mohan Joshi. "Schwannoma in a Young Male Breast: A Difficult Differential Diagnosis". Journal of Evolution of Medical and Dental Sciences 2014; Vol. 3, Issue 74, December 29; Page: 15617-15620, DOI: $10.14260 /$ jemds/2014/4109

INTRODUCTION: A benign tumour of Schwann cells of the peripheral nerve sheath is called Schwannoma, also called as neurilemoma or neurinoma. Most breast cancers and other breast tumors have an epithelial cell origin, with stromal and myoepithelial cell tumors being less common. A nerve sheath tumor arising from neural crest-derived Schwann cells within the breast is rarer still. For unknown reasons, these cells can sometimes grow in a neoplastic fashion which results in a benign tumor termed as schwannoma. Neurilemoma, neurinoma, peripheral nerve sheath tumor and schwannoma are considered to be synonymous though the term schwannoma appears to be more precise than the others as this tumour is believed to arise from schwan cells. Schwannoma are commonly slow growing solitary lesions which rarely show malignant transformation. The clinical significance of this benign tumor is that it may clinically and radiographically simulate malignant neoplasm.

CASE REPORT: An 18 year old male presented to us with history of lump in his left breast. The lump was initially noted by him 2 months back and it had not increased much in size since then. It was not associated with pain. Neither was it associated with nipple discharge or nipple retraction. There was no history of similar lump anywhere else on his body. Family history was insignificant. There was no history of intake of anabolic steroids.

On examination he had a firm, freely mobile non-tender $1 \mathrm{x} 1 \mathrm{~cm}$ lump in his left breast in the lower outer quadrant. Patient had no signs of neurofibromatosis. No evidence of axillary lymphadenopathy. X ray of chest was normal. Patient was posted for lump excision directly as it was a small lump. A well encapsulated lobulated tumor mass was removed from the breast parenchyma. Cut section of the tumor was yellowish without any degenerative changes like areas of haemorrhage or necrosis or cysts. Histological examination revealed a tumor entirely enclosed within a thick, fibrous capsule. Serial sections (Fig. 1) studied showed a spongy biphasic pattern with hypercellular and hypocellular areas with spindle cell proliferation, corresponding to Antoni A and B areas (Fig. 1) Spindle cells are wavy, slender with pointed ends often arranged in a palisading fashion or in an organoid arrangement Verocoy bodies (Fig. 2). Dilated blood vessels with hyalinized walls were noted. Histo-pathological diagnosis was breast schwanomma. Patient's further course was uneventful with no evidence of recurrence.

DISCUSSION: Schwannoma is a benign tumor of nerve cell origin. It may arise from either intracranial nerves or peripheral nerves. Shwannoma of acoustic nerve origin are most common variety seen intracranially. Peripheral schwannomas occur commonly in head, neck, flexor aspect of extremities, however any part of the body can be affected. Localization in the breast is very unusual. 
Schwannomas are often associated with a genetic condition called Neurofibromatosis-2 (NF-2), also called 'central von Recklinghausen's disease.

Breast schwannoma occur more in females than in male. Bibliographical search revealed only five case reports describing male breast shwannoma.

\begin{tabular}{|c|c|c|}
\hline AUTHOR & AGE (years) & SIZE $(\mathrm{cm})$ \\
\hline Cohen et al[1] & 75 & 9 \\
\hline Martinez et al[2] & 83 & 4 \\
\hline \multirow[t]{3}{*}{ Mondel et al[3] } & 38 & 3.5 \\
\hline & 56 & 8.6 \\
\hline & 74 & 11 \\
\hline Gupta et al[4] & 35 & 2 \\
\hline Yegane et al[5] & 57 & 4.5 \\
\hline Our case & 18 & 1 \\
\hline
\end{tabular}

As seen above most male breast schwannoma occur mostly in the older age group and size can vary from as small as $1 \mathrm{~cm}$ to $11 \mathrm{~cm}$. Our case report describes the occurrence of breast schwannoma in youngest age among those previously described and the size of the tumour was the smallest amongst all. It usually presents as a palpable breast lump which will typically be smooth, elastic-soft, mobile, and painless.

Ultrasongraphy and mammography may aid in diagnosis, however due to paucity of data the findings have not been extensively described. Mammographically, schwannomas are most commonly described as a nonspecific, well-defined, round or oval density.[6,7,8] A normal mammogram and an illdefined mass have also been reported.[9] Sonographically, more variation in appearance has been reported; however it is most commonly reported as a solid hypoechoic well-defined mass with variable posterior acoustic enhancement. ${ }^{[6,8]}$

A cytological diagnosis of schwannoma of the breast may be possible by fine-needle aspiration cytology. Findings commonly noted are clusters of interlacing bundles of spindle- shaped cells, arranged in a palisading fashion, lack of epithelial elements, and absence of mitotic activity. Primary malignant schwannomas of the breast have also been reported.[10] These tumors show no worrisome mammographic or ultrasonographic features and as such cytological features would also be similar to benign lesion. Hence formulating a definitive diagnosis based FNAC alone is not recommended.[7]

Histological examination reveals the characteristic appearance of schwannoma with Antoni A and Antoni B areas. Antoni A areas are typically composed of organised cellular component consisting of long bipolar cells that often form a pallasiding arrangement known as verocay bodies. Antoni B areas, on the other hand, are far less orderly and less cellular. They usually consist of a loose meshwork of gelatinous and microcystic tissues, with large, irregularly spaced and thick-walled blood vessels. The neoplastic cells strongly express S-100 which is in highest concentration in Antoni A areas.

Surgical excision is the best recommended treatment. It is usually curative, and it also resolves any diagnostic doubts. Prognosis for patients with solitary schwannoma following resection is excellent. Malignant transformation of a solitary lesion is rare. In this case report we conclude that 


\section{CASE REPORT}

differential diagnosis of schwannoma of breast should be kept in mind in a young male patient also and better to excise and achieve a histo-pathological diagnosis.

\section{REFERENCES:}

1. Cohen M B, Fisher P E. Schwann cell tumors of the breast and mammary region. Surg Pathol 1991; 4: 47-56.

2. Martinez-Onsurbe P, Fuentes-Vaamonde E, Gonzales-Estecha A, Hernandéz-Ortiz MJ, RuizVillaespesa A. Neurilemmoma of the breast in a man- A case report. Acta Cytol 1992; 36: 511513.

3. Mondal A, Choudhury PK. Cytologic diagnosis of neurile- momas of male breast by fine needle aspiration. Indian J Pathol Microbiol 1996; 39: 157-160.

4. Gupta RK, Naran S, Lallu S, Fauck R. Fine-needle aspiration cytology in neurilemoma (schwannoma) of the breast: report of two cases in a man and a woman. Diagn Cytopathol 2001; 24: 76-77.

5. Yegane R, Mousavian S A, Bashashati M. Rare Peripheral Nerve Schwannoma. IJCP 2009; 2: 107110.

6. N. Uchida, H. Yokoo, H. Kuwano. Schwannoma of the breast: report of a case. Surgery Today 2005; 35: 238-242.

7. G. Bellezza, T. Lombardi, P. Panzarola, A. Sidoni, A. Cavaliere, M. Giansanti. Schwannoma of the breast: a case report and review of the literature. Tumori 2007; 93: 308-311.

8. K. S. Cho, H. Y. Choi, S. W. Lee, and S. H. Sung. Sonographic findings in solitary schwannoma of the breast. Journal of Clinical Ultrasound 2001; 29: 99-101.

9. S. H. Gultekin, H. S. Cody, and S. A. Hoda. Schwannoma of the breast. Southern Medical Journal 1996; 89: 238-239.

10. Salvadori B, Greco M, Galluzzo D. Surgery for malignant mesenchymal tumors of the breast; a series of 31 cases. Tumori 1982; 68: 325-329.

Fig. 1: Tumor showing typical Antoni A \& B areas and dilated hyalinised blood vessels.

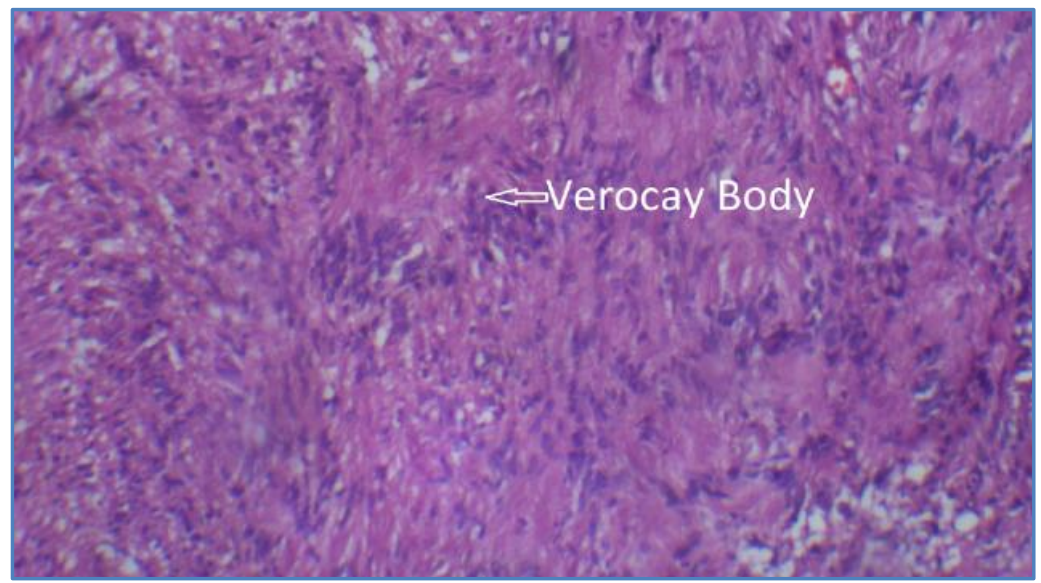

Fig. 1 


\section{CASE REPORT}

Fig. 2: Histopathological Examination showing Verocay Bodies.

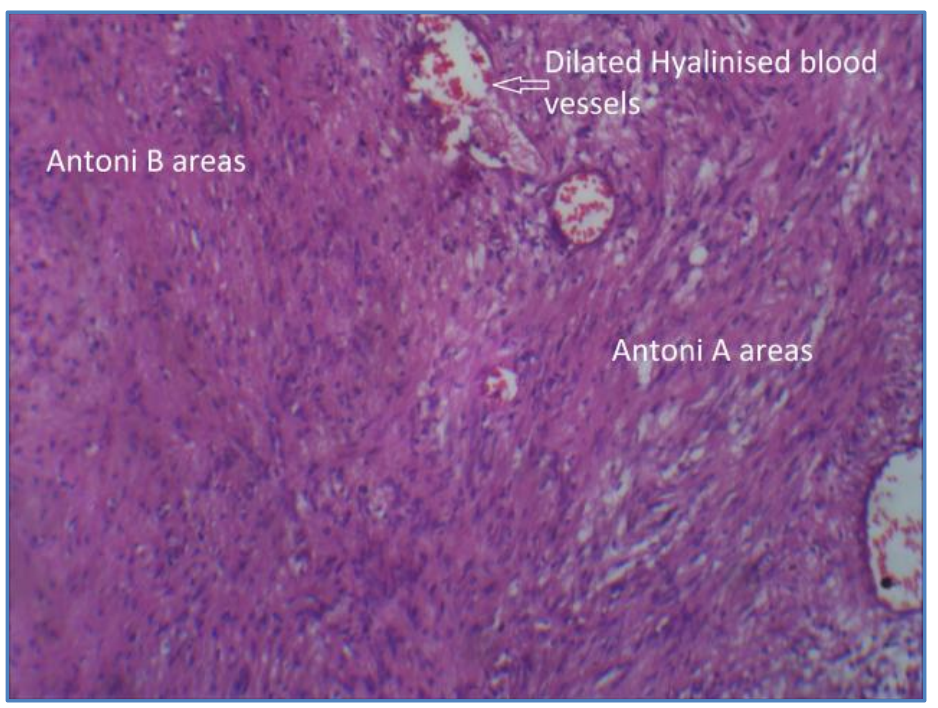

Fig. 2

\section{AUTHORS:}

1. Minakshi Gadhire

2. Prashant Rao

3. Sarika Mayekar

4. Mohan Joshi

\section{PARTICULARS OF CONTRIBUTORS:}

1. Associate Professor, Department of General Surgery, Lokmanya Tilak Medical College and Hospital, Mumbai.

2. Senior Resident, Department of General Surgery, Lokmanya Tilak Medical College and Hospital, Mumbai.

3. Senior Resident, Department of General Surgery, Lokmanya Tilak Medical College and Hospital, Mumbai.
4. Professor, Department of General Surgery, Lokmanya Tilak Medical College and Hospital, Mumbai.

\section{NAME ADDRESS EMAIL ID OF THE CORRESPONDING AUTHOR:}

Dr. Minkshi Gadhire, Room No. 25, First Floor, College Building, Department of General Surgery, Lokmanya Tilak Municipal Medical College and Hospital, Sion - 400022, Mumbai.

E-mail: gadhireminakshi@yahoo.in

Date of Submission: $11 / 12 / 2014$.

Date of Peer Review: 12/12/2014.

Date of Acceptance: 19/12/2014.

Date of Publishing: 29/12/2014. 